\title{
The digital transformation - all good?
}

\section{DOI: 10.7861/fhj.ed-7-3-1}

The theme of this issue is 'Digital health workforce'. When we decided upon this topic in 2019, we knew it to be important, but we could not have anticipated the speed in the introduction of digital technologies into our services that has been precipitated by the COVID-19 pandemic. I am therefore tremendously grateful to Sheena Visram, one of our editorial board, and Wajid Hussain, the Royal College of Physicians' (RCP's) clinical director for digital health, for jointly guest editing this issue.

Back in April, I worried that journals would be one of the casualties of the pandemic. Paralleling many predictions made in those early weeks of the pandemic, I was completely wrong. We have seen a $400 \%$ increase in submissions matched by social media activity (@FutureHealth]) and downloads from our website (www.rcpjournals.org/content/futurehosp). In response, we have accelerated the development of our online resources. The COVID-19 online subject collection (www.rcpjournals.org/ covid-19), shared jointly with Clinical Medicine is filled with articles around clinical activity, service changes, personal experience and reflection. While primarily I am grateful to authors, the editorial process would have faltered were it not for the exceptional work of the editorial team at the RCP. Indeed, we have actually been able to publish accepted papers more quickly than ever before. The support I have received from the editorial board has been invaluable, and I also offer thanks to our reviewers. As part of our response, we welcome two new members to our editorial board, Rose Penfold and Linford Fernandes. Both are senior trainees with outstanding portfolios and refreshing ideas to evolve the journal.

Communication has certainly changed, not least between healthcare professionals and patients. In my last editorial, I posed a question about the legacies of the pandemic. Flexible consultations with patients are here to stay and this is seen as beneficial by patients and their healthcare professionals. I worry however about proposals that the default mode of consultation between a doctor and a patient should be virtual. As a journal that aims to publish evidence about changes in healthcare, I am concerned that such a fundamental change may be implemented without adequate evaluation.

Frances Bennett et al report on a service to tackle polypharmacy. Polypharmacy falls into the category of 'too much medicine' about which I am greatly vexed. What is the link to my concerns about the demise of face-to-face consultations? A face-to-face medication review is not only is an opportunity to protect from inappropriate prescribing, but a chance to review the patients wellbeing, detect frailty, discuss prevention, diet and exercise, and introduce a conversation about advance planning, all of which are difficult to address in a consultation precipitated by acute illness. Yet recent events have highlighted how essential all these elements are to optimal healthcare provision.
Amir Aziz and colleagues reports the impact of introducing a consultant of the week to medical wards. ${ }^{2}$ This service model is now widespread but far from universal. In accordance with my earlier comments, I think it is important that we collect and publish data to show the effectiveness of changes to services. Therefore, this paper, reporting reductions in length of stay and improved trainee experience, is a valuable addition to the body of evidence supporting this model.

With so much pressure on space, we have been sure to include articles about key rolling themes for the $\mathrm{FH}$ in this issue, including training, quality improvement and patient experience. Amy Davies and Phillip Harvey report on interest in the chief registrar scheme in areas of low uptake. ${ }^{3}$ Despite wide publicity, there is still work to be done to improve uptake and applications to the scheme, which has been one of the great training innovations and opportunities in recent years.

It is vital that patients remain central to understanding the impact of changes to services. Parker O'Neill and colleagues report patient perspectives on social media-delivered telemedicine for inflammatory bowel disease. ${ }^{4}$ This study, conducted before the pandemic, identified that $60 \%$ patients use social media for information about their illness, a figure likely to be even higher now. Healthcare professionals need to acknowledge and embrace social media in caring for patients with chronic disease, one of the many facets of digital healthcare. We are keen to expand the quantity and quality of papers reporting patient experience in our journal and I would encourage authors to always consider patient involvement and perspectives in their research designs and submissions.

A concern linked to the changes to healthcare in recent months has been the importance of ensuring some groups of patients and users are not disadvantaged by the redesigns. Inequality is therefore the very timely theme of our next issue. Meanwhile, I hope you find there is much in this issue and in the $\mathrm{FH}$ J online to enjoy.

Dr Kevin Fox Editor-in-chief

\section{References}

1 Bennett F, Shah N, Offord R, Ferner R, Sofat R. Establishing a service to tackle problematic polypharmacy. FHJ 2020;7:208-11.

2 Aziz A, Hawkins A, Gainer $Y$ et al. General medicine consultant of the week model shortens hospital length of stay and improves the patient journey. FHJ 2020;7:218-21.

3 Davies A, Harvey P. Survey of the understanding and interest in the chief registrar scheme from doctors in an area of low uptake. FHJ 2020;7:222-5.

4 O'Neill P, Shandro B, Poullis A. Patient perspectives on social media delivered telemedicine for inflammatory bowel disease. $\mathrm{FH}]$ 2020;7:241-4.

Members of the editorial board

Suzie Bailey

Rodger Charlton

Mohsin Choudry

John Dean

Julia Ellis

Linford Fernandes
Graham Foulkes

Kevin Fox

Rose Penfold

Anenta Ramakrishnan

Joanna Szram

Mark Temple
Louella Vaughan

Emma Vaux

Sheena Visram

Katharine Warburton

Stephen Webb 